\title{
Evaluation of the role of tongue flap in recurrent large palatal fistula repair
}

\author{
Original Mohamed Abdeldayem \\ Article \\ Department of Maxillofacial and Plastic Surgery, Alexandria University, Alexandria,
Egypt
}

\begin{abstract}
Background: The formation of the palatal fistula is a known complication of palatoplasty. The most frequent risk factors are vascular accidents, poor surgical technique, or even infection. However, large recurrent fistula showed poor prognosis with local flaps.

Objective: This study aims to evaluate the role of tongue flap in recurrent large palatal fistula repair.

Patients and Methods: The author recruited 15 pediatric patients during a period of fourteen-month. The primary diagnosis of the included sample was a non-native recurrent palatal fistula. Tongue flap repair of the recurrent palatal fistula was performed in all 15 patients. The flaps were separated after three weeks, and the final inset was done. Flap viability, fistula closure, residual tongue function, operation time, and speech problems were assessed.

Results: In all the patients, the fistula was closed primarily by tongue flap. None of the patients developed flap necrosis. Neither donor-site morbidity nor functional deformity of the tongue was seen. The operative time ranged from 40 minutes up to 60 minutes in $87 \%$ of the patients. The speech was improved in all cases.

Conclusion: The excellent vascularity, central position, mobility, and versatility of the tongue flap make it the perfect choice for repairing large fistula in palates injured by previous surgery. Children very well tolerate it. We, therefore, recommend tongue flap for large recurrent palatal fistula in children.
\end{abstract}

Key Words: Cleft palate, Palatal fistula and Tongue flap.

Received: 20 February 2021, Accepted: 18 April 2021.

Corresponding Author: Mohamed Abdeldayem, Department of Maxillofacial and Plastic Surgery, Faculty of Dentistry, Alexandria University, Alexandria, Egypt, Tel.: +2034864640, Mobile: +201221999131, E-mail: dr_morsi_80@hotmail. com.

ISSN: 2090-097X, January 2021, Vol. 12, No. 1

\section{INTRODUCTION}

A palatal fistula is an abnormal breakup between the nasal and the oral cavities. After primary surgical repair, a fistula can develop or be induced by cysts, trauma, radiation, neoplasm, or rare infectious diseases as granuloma, leprosy, and syphilitic gumma ${ }^{[1]}$. It is difficult to ascertain the true incidence of fistula formation after primary palate repair because the research articles vary considerably, reported incidences over in the literature have ranged from $5 \%{ }^{[2]}$ up to $50 \%$ with one-stage closures in a review article by Shultz ${ }^{[3]}$. Bremner and Musgrave studied the incidence of fistula formation for bilateral clefts in the palate to be $12.5 \%$, about $8 \%$ for unilateral clefts, and $5 \%$ in the secondary palate isolated cleft $^{[2]}$.

In the early nineteenth, Eiselberg was one of the few to present intra-oral defect repair tongue flaps ${ }^{[4]}$. As a matter of fact, Guerrero-Santos and Altamirano were the first to report specific lingual tissue recruitment for the closure of hard palate fistulas ${ }^{[5]}$. Cadenat et al. defined the rich submucous vascular plexus located in the tongue. It enables safe and predictable lifting of thin flaps. These authors give rise to the tongue's rich sub-mucosal plexus that enables random pattern flaps to be used without limitation in angles or directions ${ }^{[6]}$. This tongue flap quality makes it quite versatile during oral reconstruction. Furthermore, the tongue flap can be adjusted to accommodate irregular fistulae. The paramedian or central tongue flap is an altered pattern flap known to have strong vascularity from lingual artery branches ${ }^{[7]}$. Their large tissue content and excellent vascularity make them a valuable resource for the reparation of large fistulae in palates injured from prior intervention. Furthermore, no reports show that removing large segments from the mother tongue leads to any movement or speech impairment ${ }^{[8]}$. This retrospective study evaluates the efficacy of tongue flaps in secondary palatal defects. The included patients' assessment was flap viability, cessation of fluids and food from the nose, speech improvement, donor site morbidity, and oral bleeding.

\section{PATIENTS AND METHODS}

Fifteen patients with secondary recurrent palatal fistula were operated on with tongue flaps according to the fistula's location. The eligible participants for the study were to 
have patients with [a] the previous repair of cleft palate and fistula and $[\mathrm{b}]$ age $<7$ and both sexes.

The operation was performed with endotracheal intubation under general anesthesia. For homeostasis and tissue ballooning for ease of dissection, incision lines of the fistula were injected with 1:200,000 adrenalin and 2\% Lidocaine.

While exposing the recurrent anterior palatal fistula (Figure 1), the fistulous tract was incised and edges were excised. Using 40-Vicryl, the nasal floor was preserved. To deliver the oral lining, the tongue flap was harvested (Figure 2). The flap length was adjusted long enough to fill the fistula's anteroposterior dimensions and an additional $1 \mathrm{~cm}$ to allow the flap to turn smoothly. The flap width was defined by the defect width plus 20 percent,

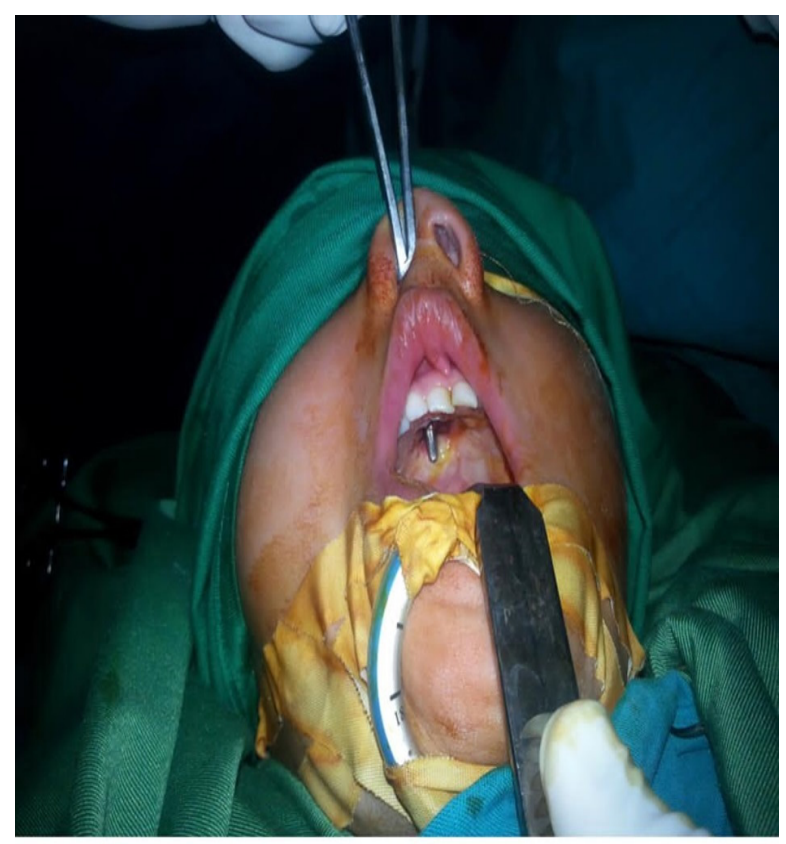

Figure 1: Recurrent anterior palatal fistula.

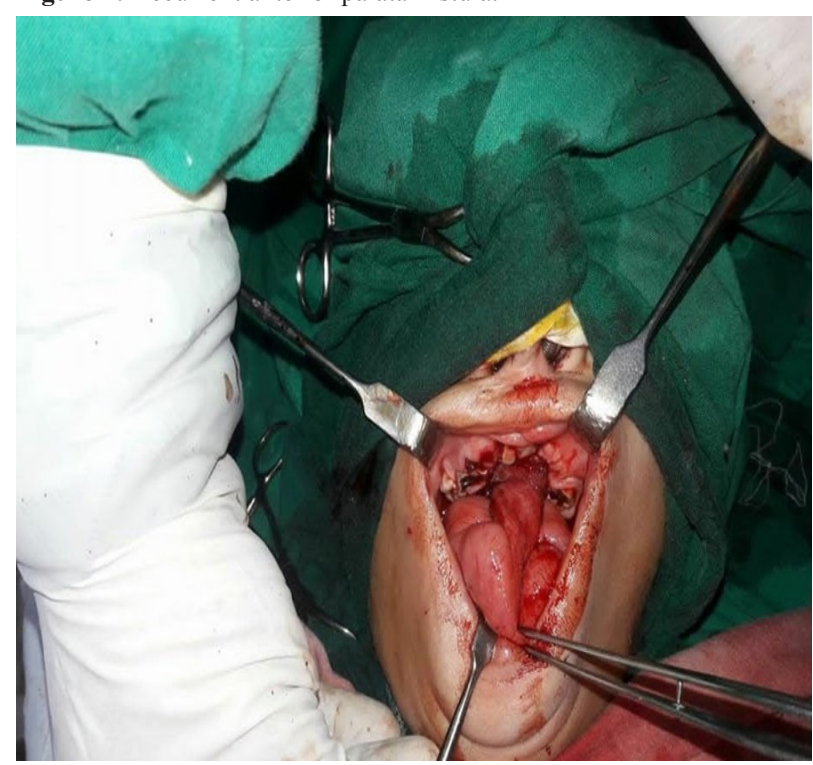

Figure 3: Tongue flap covering fistula site. but the tongue width never exceeded more than $2 / 3^{\text {rd }}$. To protect the underlying submucosal plexus, flaps with up to $5-7 \mathrm{~mm}$ muscle thickness were raised (Figure 3). With Vicryl 4 - 0 interrupted sutures, donor-site closure was performed (Figure 4), taking care not to close it too firmly near the pedicle, thus protecting the flap vascularity. The tongue flap was then tilted forward and sutured anteriorly and outwards using 4 - 0 Vicryl to the raw edges of the palatal defect (Figure 5). A proper edge-to-edge approximation of the flap's margins to the mucoperiosteal margins is confirmed after two weeks of follow-up (Figure 5). The flaps were separated after three weeks, and the final inset was done (Figure 6). Flap viability, fistula closure, residual tongue function, and speech problems were assessed.

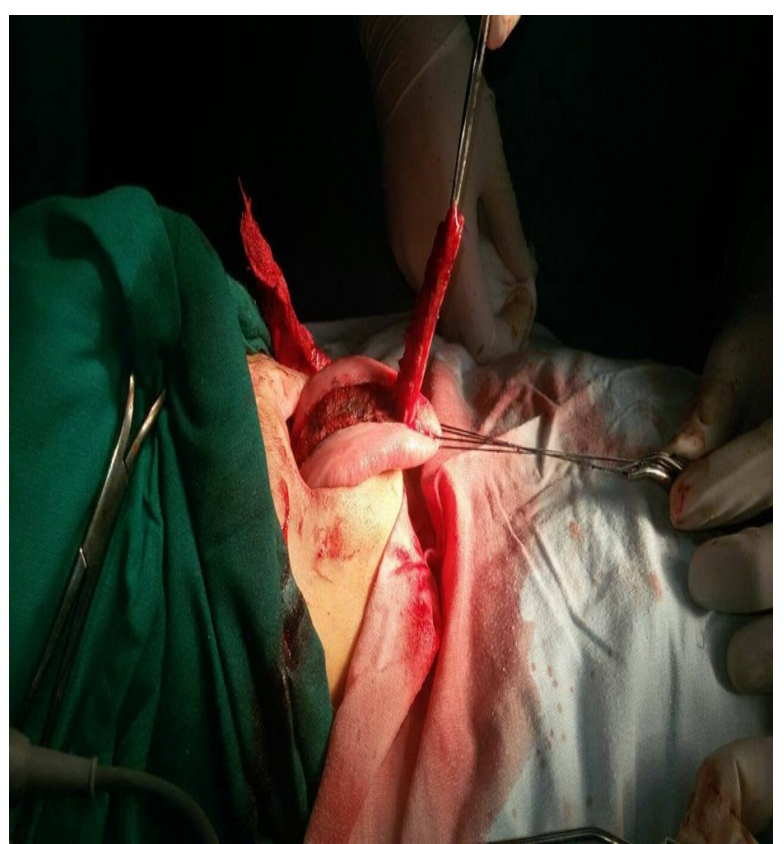

Figure 2: Tongue flap harvest.

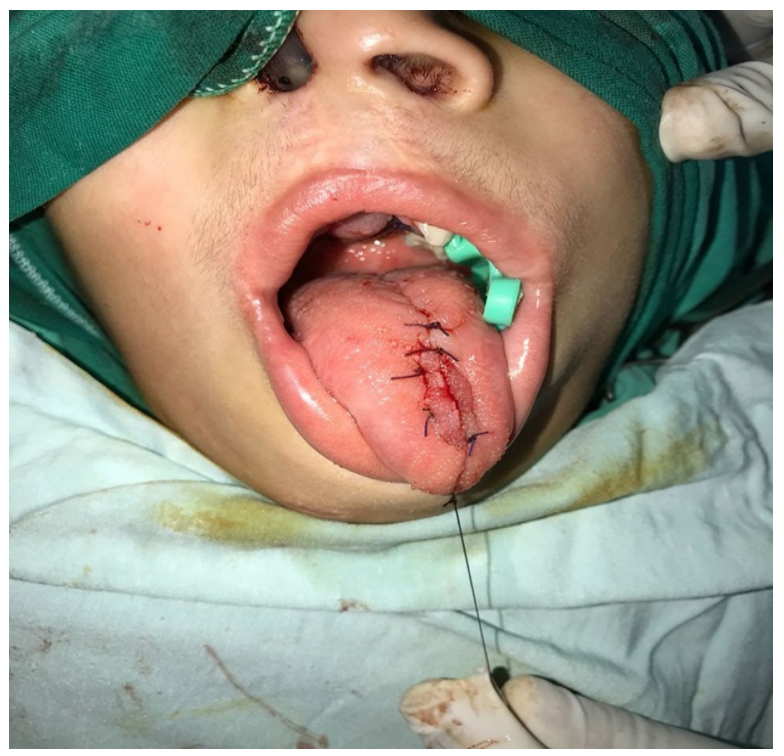

Figure 4: Donor site closure. 


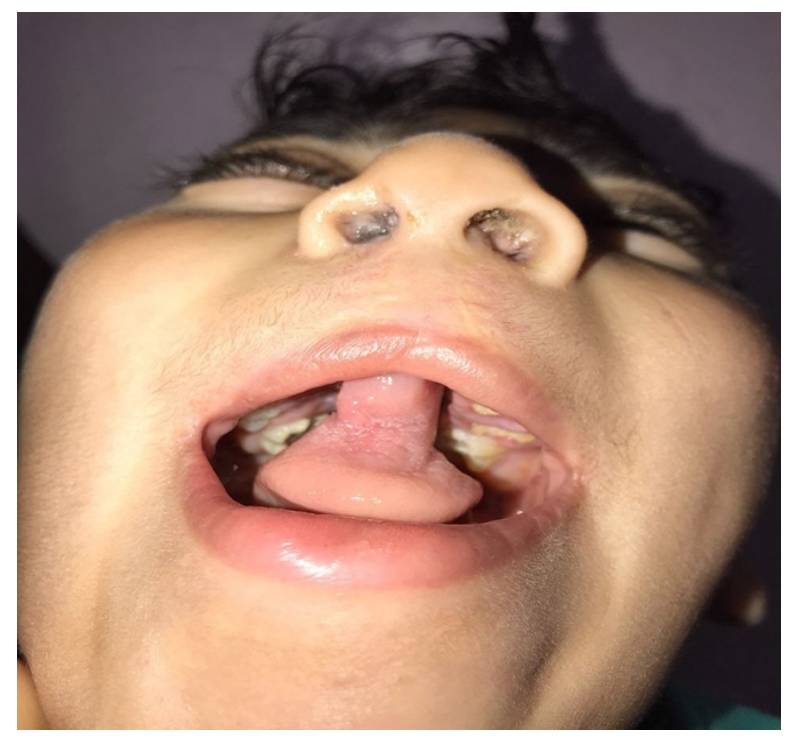

Figure 5: Tongue flap follow up 2 weeks PO.

\section{RESULTS}

The age range in this study was between 2 and 6 years with mean $\pm \mathrm{SD}=3.6 \pm 1$. and the mean fistula size was $4.2 \pm 1.4$. Out of the group of 15 patients, 8 were male $(53.3 \%)$ and 7 were female $(46.7 \%)$. The majority of the patient had undergone less than two previous operations ( $80 \%$ ), the flab was viable in the whole 15 patients.

The operative time of tongue flap in recurrent palatal fistula repair for 13 (86.7 \%)patients ranged from 40 minutes up to 60 minutes only two cases operative time was exceeding 60 minutes In addition, none of the patients needed blood transfusion due to meticulous dissection. Moreover, all of them showed cessation of fluid and food regurgitation from the nose and nasality improvement. None of the patients experienced donor site morbidity nor PO bleeding. The speech was improved in all cases comparing it with the speech of child's peers.

\section{DISCUSSION}

Repairing oroantral and oronasal deformities is difficult and challenging in the oral and maxillofacial surgery field ${ }^{[9]}$. The development of these fistulae has been attributed to diverse causes. Poor surgical techniques (strain on the suture line, inadequate mobilization, damage to the mucoperiosteal flaps vascularization, etc.), extensive denudation of the palatal bone, hematoma, single layer cleft closure, and infection are some of the causes of secondary fistula ${ }^{[10]}$. Poor supply of blood is one of the contributing factors to fistula closure failure ${ }^{[12]}$. Instrumental trauma to palatal flaps margins during the operation, seriously flawed suturing, the wrong reflection of the sub-periosteal flap and wrongful closure ${ }^{[11]}$, wound healing disruption, necrosis, and insufficient palatal tissue attachment to the nasal mucosa. Meanwhile, the cleft area's fundamental tissue reduction factor is considered the primary risk factor ${ }^{[13]}$.

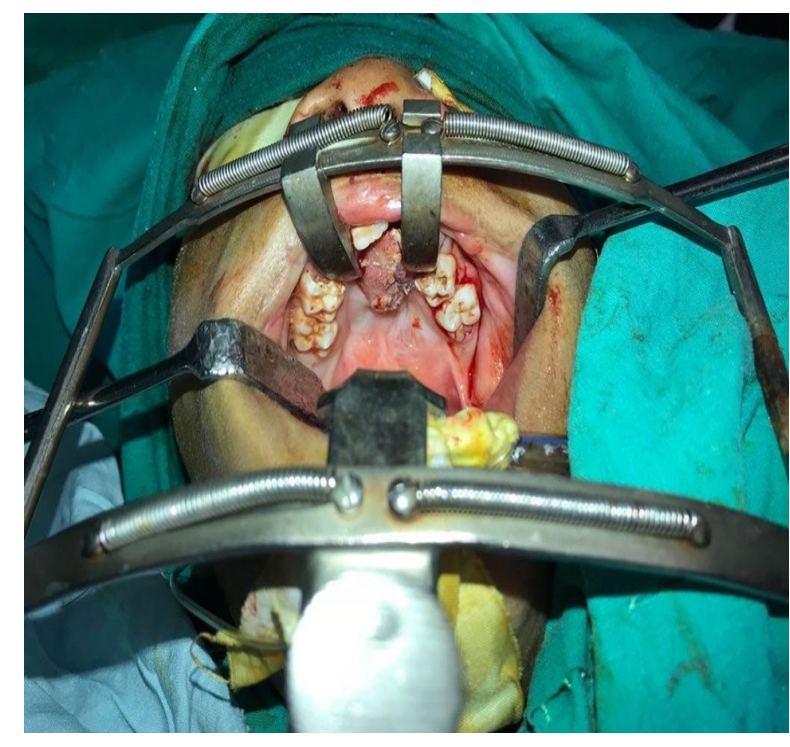

Figure 6: Tongue flap separation 3 weeks PO.

Ideally, a complete separation of the oral and nasal cavities is the initial rationale of treatment in the management of the cleft palate, but different studies have reported a high percentage of palatal fistula formation of up to $34 \%{ }^{[14,15]}$ and $50 \%$ with one stage closure ${ }^{[3,16]}$. Even in the best of hands, repair of such fistulas can be tricky ${ }^{[17]}$. In this study, tongue flaps were used when the closure had previously occurred and was a failure.

In the treatment of defects of the hard palate, anterior buccal mucosa, lips, and anterior floor of the mouth, anteriorly based flaps are useful. Assuncao has reported closing large anterior palatal fistulas with thin tongue flaps [3 $\mathrm{mm}]$. The results of this series confirm that the fine tongue flap is a safe and reliable method for closing large palate fistula, even if adapted to fit irregular defects ${ }^{[18]}$. To avoid swallowing and articulation problems, an optimal thickness of $5-7 \mathrm{~mm}$ is required during the elevation of the tongue flap ${ }^{[19]}$. We performed the flap flush on the adjacent palatal tissues in all our patients, and no one complained of any problem due to the bulky flap. The nasal layer was properly and extensively undermined to help tensionfree closure ${ }^{[19]}$. We used coating sutures in our patients to correctly applied margins, and our success rate was $100 \%$. Additionally, the author neither put any nasogastric tube nor fixed the tongue with any suture because the tongue flap is well tolerated and safe for children ${ }^{[19]}$.

Different authors divided flaps into two parts, ranging from 10 to 21 days ${ }^{[20,21]}$. In this study, we decided to divide the flap by three weeks, in line with previously reported studies. The reason for flap division at the third week is spontaneously marginal necrosis healing during this time frame.

A tongue flap causes no significant donor morbidity. Hematoma formation, sloughing of the graft, epistaxis, and flap dehiscence are major complications. There is no speech 
or movement impairment, and only transient loss of tongue sensation and taste can occur. A slightly narrower tongue seems to be the only residual defect of the procedure ${ }^{[22]}$. No operational defect of the tongue was identified in any of our patients. In all patients, the taste sensation and swallowing reflex were also found to be normal.

\section{CONFLICT OF INTEREST}

The authors declare no conflict of interest.

\section{REFERENCES}

1. Gupta N, Shetty S, Degala S. Tongue flap: a "workhorse flap" in repair of recurrent palatal fistulae. Oral Maxillofac Surg. 2020 Mar; 24 (1): 93101-. doi: 10.1007/s100069-00823-019. Epub 2020 Jan 6. PMID: 31907677.

2. Musgrave RH, Bremner JC. Complications of cleftpalate surgery. Plast Reconstr Surg 1960; 26: $180-9$.

3. Schultz RC. Management and timing of cleft palatefistula repair. Plast Reconstr Surg 1986; 78: $739-45$.

4. Buchbinder D, St-Hilaire H (2003) Tongue flaps in maxillofacialsurgery. Oral Maxillofac Surg Clin N Am 15: 475 - 4866.

5. Steinhauser EW (1982) Experience with dorsal tongue flaps forclosure of defects of the hard palate. J Oral Maxillofac Surg 40: 787 - 789.

6. Cadenat H, Combelle R, Fabie M, Lambeaux de langue (1973)Vascularisation, morphologie et utilisation. Ann Chir Plast 18: 223 - 227.

7. Shangkuan $\mathrm{H}$, Xinghai $\mathrm{W}$, Zengxing $\mathrm{W}$ et al (1998) Anatomic basesof tongue flaps. Surg Radiol Anat 20: 83.

8. Kinnerbrew MC, Malloy RB (1983) Posteriorly based, lateral lin-gual flaps for alveolar cleft bone graft coverage. J Oral Maxillofac Surg 41: $555-561$.

9. Smith TS, Schaberg SJ, Collins JT (1982) Repair of a palatal defectusing a dorsal pedicle tongue flap. J Oral Maxillofac Surg 40: 670 - 673.

10. Jackson IT, Fasching MC (1990) Secondary deformities of cleft lip,nose and cleft palate. In: JG
MC, May JW Jr, Litter JW (eds) Plasticsurgery, vol 4. Cleft lip and palate and craniofacial anomalies, chapt56. Saunders, Philadelphia, p 2771.

11. Lehman JA, Curtin P, Haas DG (1995) Closure of palatal fistulas.Oper Tech Plast Reconstr Surg 2: $255-262$.

12. Ogle OE (2002) The management of oronasal fistulas in the cleftpalate patient. Oral Maxillofac Surg Clin N Am 14: 553 - 562.

13. Tessier P (1976) Anatomical classification of facial, craniofacialand laterofacial clefts. J Maxillofac Surg 4: 69.

14. Posnick JC, Getz SB (1987) Surgical closure of end stage palatalfistulas using anteriorlybased dorsal tongue flap. J Oral Maxillofac Surg 45: $907-912$.

15. Denny AD, Amm CA (2005) Surgical technique for the correctionof postpalatoplasty fistulae of the hard palate. Plast Reconstr Surg 115: $383-387$.

16. Abyholm FE, Borchgrevnik HH, Eskeland G (1979) Palatal fistulaefollowing cleft palate surgery. Scand J Plast Reconstr Surg 13: 295.

17. 1Wilhelmi BJ, Appelt EA, Hill L, Blackwell SJ (2001) Palatal fistu-las: rare with the two-flap palatoplasty repair. Plast Reconstr Surg107: $315-318$.

18. Assunçao AG. The design of tongue flaps for the closure of palatal fistulas. Plast Reconstr Surg. 1993; 91: $806-10$.

19. Mahajan RK, Chhajlani R, Ghildiyal HC. Role of tongue flap in palatal fistula repair: A series of 41 cases. Indian J Plast Surg. 2014; 47: 210 - 5.

20. Murthy J. Descriptive study of management of palatal fistula in one hundred and ninety-four cleft individuals. Indian J Plast Surg. 2011; 44: $41-6$. [PMC free article] [PubMed] [Google Scholar].

21. Sadhu P. Oronasal fistula in cleft palate surgery. Indian J Plast Surg. 2009; 42 Suppl: S123 - 8.

22. Vasishta SM, Krishnan G, Rai YS, Desai A. The versatility of the tongue flap in the closure of palatal fistula. Craniomaxillofac Trauma Reconstr. 2012; 5: $145-60$. 